Document downloaded from:

http://hdl.handle.net/10251/63638

This paper must be cited as:

Serrano Jareño, MA.; Cañada Ribera, LJ.; Moreno Esteve, JC. (2012). Solar UV exposure of children in a summer school in Valencia, Spain. International Journal of Biometeorology. 56:371-377. doi:10.1007/s00484-011-0440-7.

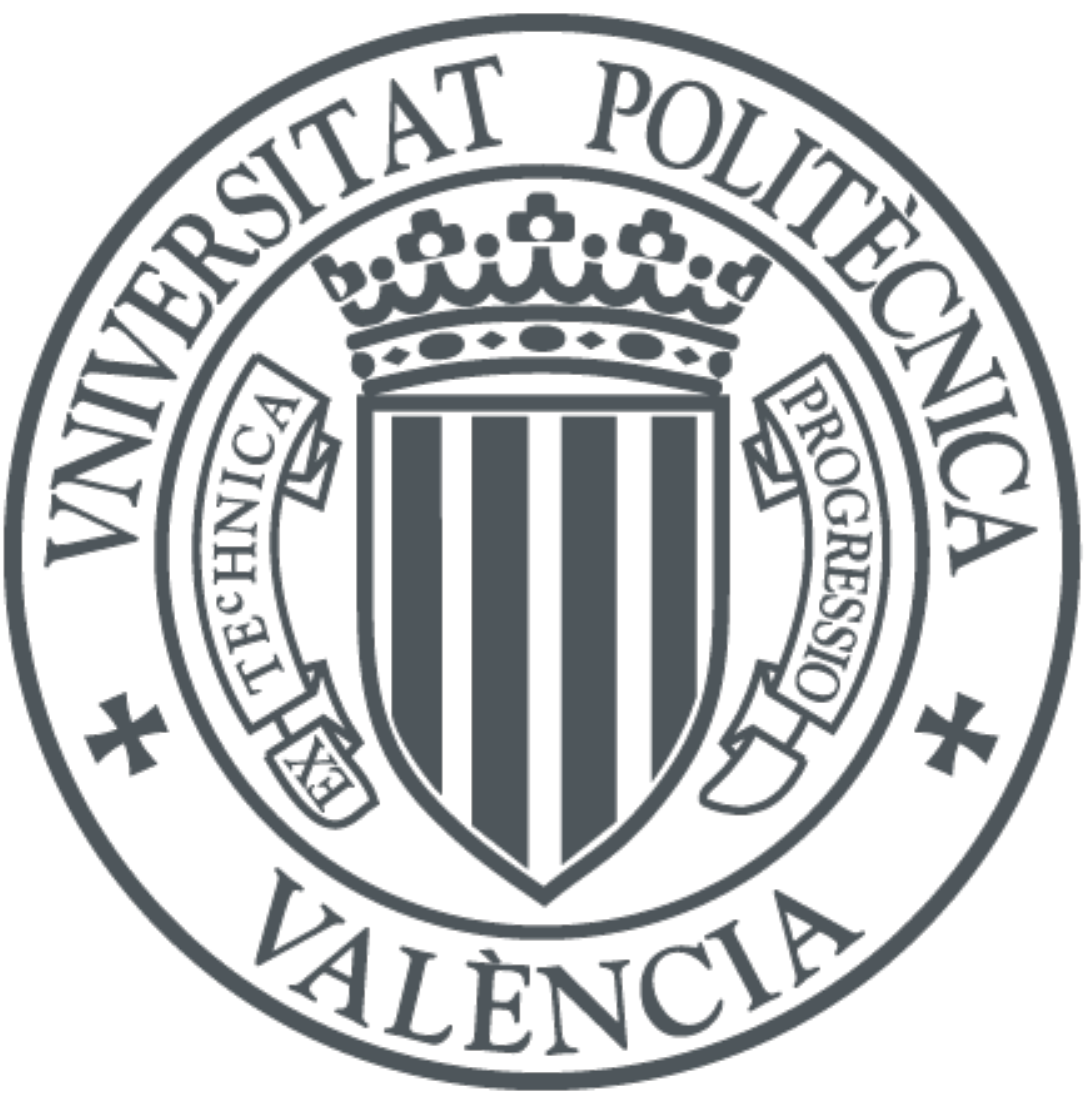

The final publication is available at

http://dx.doi.org/10.1007/s00484-011-0440-7

Copyright Springer Verlag (Germany)

Additional Information 


\title{
Solar UV Exposure of Children in a Summer School in Valencia, Spain.
}

\author{
María-Antonia Serrano, ${ }^{1 *}$ Javier Cañada, ${ }^{2 \star}$ Juan Carlos Moreno $^{1 \star}$ \\ ${ }^{1}$ Department of Applied Physics, Universidad Politécnica de Valencia, Camino de Vera s/n, \\ 46022 Valencia, Spain \\ ${ }^{2}$ Department of Applied Thermodynamics, Universidad Politécnica de Valencia, 46022

$$
\text { Valencia, Spain }
$$ \\ ${ }^{\star}$ Members of the Valencia Solar Radiation Research Group \\ *Corresponding author: : Tel: +34-963877007; Fax: +34-963879896, \\ e-mail: mserranj@fis.upv.es (Maria-Antonia Serrano).
}




\begin{abstract}
Ultraviolet (UV) exposure is the major environmental factor involved in the development of skin cancers and occurs mainly during outdoor activities. During summer schools, children receive regular and significant solar ultraviolet erythemal radiation (UVER) while practicing outdoor activities. Personal dosimeters (VioSpor) were attached to the shoulders of schoolchildren and used to quantify their exposure to UVER. The study took place in Valencia, Spain, during July 2008, with three age groups (7-8, 9-10 and 11-12 year-olds) and involved about 15 schoolchildren. The median (25, 75 percentile) two-daily UV exposure values for all groups was $5.49(3.59,8.00)$ standard erythemal doses (SEDs), where 1 SED is defined as effective $100 \mathrm{Jm}^{-2}$ when weighted with the CIE erythemal response function. Exposure ratio (ER) is defined as the ratio between the personal dose on a selected body site and the corresponding ambient dose received on a horizontal plane during the same exposure period. The median $(25,75$ percentile) ER value for all groups in the study was $5.9(4.1,8.7) \%$.
\end{abstract}

Keywords: ultraviolet erythemal radiation; UVER exposure; exposure ratio; Personal dosimetry; schoolchildren; Viospor. 


\section{Introduction}

The Summer School of the Universidad Politécnica de Valencia (UPV), Spain (39²8 ' $49^{\text {" N), }}$ is responsible for organizing various socio-cultural programs in order to cover holiday periods for children and brethren of members of the university community.

The service provided is the organization and development of various leisure activities and free time for children and young people aged between 4 and 17 during the month of July. Users are the UPV community and society in general. Participants in the summer school are divided into groups according to their age, and each group is assigned a minimum of two people (monitors) for the control of children and the organization of leisure activities.

In the summer school of the UPV, children do all sorts of activities both indoors and outdoors, off-campus excursions, and take baths in the indoor pool. Children at this summer school receive regular and significant solar ultraviolet erythemal radiation (UVER) in the many activities that take place outdoors. Exposure of skin to UV radiation is an important risk factor in the development of melanoma and other skin cancers, as well as skin photoaging and eye damage (Armstrong 2005; Armstrong and Kricker 2001; IARC 1990). The aim of this article is to study the UVER exposure of children during their recreational activities in a summer school in Valencia (Spain). To quantify the children's exposure to UVER received during these outdoor activities, sensitive spore-film filter-type personal dosimeters (VioSpor) were used to measure the biologically effective UV radiation. In addition, the monitors (one monitor per group) of these groups were invited to participate. This enabled a comparison of the children's exposures to be made with those of the older group, while taking into account that the monitors 
attached the dosimeters to their wrists. To make the measurements, those days dominated by outdoor activities in the campus of the UPV have been selected.

Many studies have measured UVER exposure in children and adolescents, as solar radiation exposure during youth, rather than in adult life, is believed to be more crucial for the development of cutaneous melanoma (Armstrong 2005; Oliveria et al. 2006). It has also been estimated that $25 \%$ of an individual's cumulative lifetime UV exposure occurs before the age of 18 (Saraiya et al. 2004). A review of some 30 studies on exposure to solar ultraviolet radiation in young people has recently been published (Wright and Reeder 2005). Some of these studies on individual solar UVER exposure used personal dosimeters on schoolchildren and adolescents (Guy et al. 2003; Kimlin and Parisi 2001; Ono et al. 2005; Thieden et al. 2004)

Although it is difficult to compare results from different studies, due to the different approaches and methods used, exposure ratio (ER) was chosen to minimize the effects of latitude and time of day. ER is defined as the ratio between the personal dose on a selected body site and the corresponding ambient dose on a horizontal plane during the same exposure period.

As our work was made in a summer school, comparison was made with other studies made in the summer. Mean ER for primary schoolchildren on summer weekdays tends to lie within a range of between 2.8-4.5\% in South Africa (Guy et al. 2003), and 4.6\% in Australia (Kimlin et al. 2001). In another work, in Japan (Ono et al. 2005), the weekly mean of daily UV exposure in summer (July) was in a range of 91-170 J/m². In Denmark (Thieden et al. 2004), the ER in July was $6.4 \%$ for all study subjects, including children from 4 to 15 . In Valencia (Spain) (Serrano et al. 2011) the ER in late spring was $6.1 \%$ for children from 6 to 8 years old and $4.5 \%$ for children from $10-11$ years old. 
In New Zealand (Wright et al. 2007) mean total daily exposure from late spring to early autumn was $4.9 \%$ of the ambient UVER.

Some exposure of skin to solar UV radiation stimulates the synthesis of Vitamin D (Norval et al. 2007) and is good for human well-being and required for skeletal health. This is especially important for growing children and it has been suggested that there may be beneficial properties against breast and colon cancers in adulthood (Grant and Holick 2005). Individual UV exposure was measured using sensitive spore-film filter-type personal dosimeters (VioSpor) and analyzed as a function of age and gender. Dosimeters can be used effectively for personal UV measurements in outdoor occupations (Moehrle and Garbe 2000; Moehrle et al. 2003; Moehrle et al. 2003; Serrano et al. 2009), recreational activities ( Moehrle and Garbe 2000; Thieden et al. 2000; Serrano et al. 2010), and school activities (Boldeman et al. 2004; Ono et al. 2005; Serrano et al. 2011). They are easy to place and manage; and have a spectral sensivity profile similar to erythema-weighted data calculated from spectral measurements.

\section{Materials and methods}

\section{Study location}

The study was performed in the campus of the Universidad Politécnica de Valencia, Spain (coordinates $0^{\circ} 20^{\prime} 18^{\prime \prime} \mathrm{W}, 39^{\circ} 28^{\prime} 49^{\prime \prime} \mathrm{N}, 15 \mathrm{~m}$ above sea level), to the north of the city of Valencia, far from industrial areas and near to open country. The study was carried out in a month of the summer season, July 2008. 
Subjects and design

Several groups of subjects were identified using similar age breakdowns to previous studies, such as Guy et al. (2003). The three age groups were 7-8 (group 1), 9-10 (group 2), and 11-12 year-olds (group 3). Subject recruitment was made on a volunteer basis and included written consent from the parents of participating children. The first meeting was with the head monitor to explain the requirements of the study and to ask for volunteers. A subsequent meeting took place to inform the monitors of each age group about the details of the study. The monitors kept a diary of when dosimeters were put on and removed, and the number of hours spent outdoor. The children's skin types were identified by the authors according to Fitzpatrick's classification (Fitzpatrick et al. 1974). Monitors were instructed not to change their activities during the measurement sessions and to continue with their normal routines.

The summer school takes place in the month of July and in this month in Valencia, most days are clear. The days of measurement were chosen according to the activities schedule of the students as they have hiking, camping, swimming, etc..., and we just performed measurements the days that the children were engaged in activities entirely on the campus of the UPV. The individual cumulative solar UVER exposure was measured by a VioSpor (Biosense 2010) dosimeter Type II, changed every two days. Dosimetry of ambient UVER was performed simultaneously at the weather station of the Technical School of Industrial Engineering of Valencia (TSIE), coinciding with the measurement sessions in the summer school. Children wore the UVER dosimeters on their shoulders throughout their summer school day from 9:00 a.m. to 2:00 p.m. The shoulder was chosen as it receives the highest level of UVER exposure being similar to the head which is often protected by a hat or similar. A monitor for each group 
wore the dosimeters attached to Velcro straps on the wrist, which is considered a practical and suitable anatomical site for measuring solar ultraviolet radiation exposure (Thieden et al. 2000).

Table 1 shows the measurement dates for each group and the number of children who participated in the study from each age group.

$\langle$ Table 1>

\section{Personal UVER dosimeters}

A UV sensitive spore-film filter system (VioSpor Blue Line Type II Dosimeter, Bio-Sense, Bornheim, Germany) (Biosense 2010) was used as the UV dosimeter. Spore-film production (DNA repair-deficient strain of Bacillus subtilis) and development of the films are described in (Furusawa et al. 1998; Munakata et al. 1998). The spore films are covered by a filter system with optical properties simulating the erythemal response of human skin in accordance with the CIE reference spectrum (McKinlay and Diffey 1987). The films are mounted in waterproof casings with a diameter of $32 \mathrm{~mm}$. The units of solar erythemal exposure are given by the manufacturer as $\mathrm{J} / \mathrm{m}^{2}$ and minimal erythema dose (MED) for skin type II. One MED corresponds to $250 \mathrm{~J} / \mathrm{m}^{2}$ normalized to $298 \mathrm{~nm}$, which is the dose that causes redness in nontanned Caucasian skin (skin type II) with sharply defined edges 24 hours after sun exposure. The measurement range of the dosimeter is from $10^{-3}$ to $10^{1} \mathrm{~W}_{\mathrm{CIE}} / \mathrm{m}^{2}$, corresponding to 0.05 $\mathrm{MED} /$ hour and $1000 \mathrm{MED} /$ hour, respectively, where $\mathrm{W}_{\mathrm{CIE}} / \mathrm{m}^{2}$ corresponds to the erythemal irradiance in accordance with the CIE reference spectrum (McKinlay and Diffey 1987). According to the manufacturer, the working range is 0.4-22 MED (type II) and measurement 
error is $\pm 10 \%$. The response is independent of humidity and temperature from $-20^{\circ} \mathrm{C}$ to $50^{\circ} \mathrm{C}$ (Biosense 2010). The measurements were expressed as a standard erythema dose (SED) of biologically effective ambient solar UV radiation, where 1 SED is defined as effective 100 $\mathrm{J} / \mathrm{m}^{2}$ (International Commission on Illumination 1997) when weighted with the CIE erythemal response function (McKinlay and Diffey 1987).

Ambient UVER exposure

One Type II dosimeter was set up on a horizontal plate at intervals of several days to measure UV radiation at the same time the readings were taken from the subjects. The dosimeters were located on the roof of the TSIE station (coordinates $0^{\circ} 20^{\prime} 18^{\prime \prime} \mathrm{W}, 39^{\circ} 28^{\prime} 49^{\prime \prime} \mathrm{N}, 15 \mathrm{~m}$ above sea level) in the campus of the Universidad Politécnica de Valencia, to the north of the city of Valencia, far from industrial areas and near open country.

Other ambient UVER readings were taken from a YES UVB-1 radiometer, belonging to the UVB measurement network of the regional Valencia government (GV) (Programa meteorología 2010). This was located at $00^{\circ} 20^{\prime} 09^{\prime \prime} \mathrm{W} 39^{\circ} 27^{\prime} 49 \mathrm{~N}$ on a flat building roof in the city of Valencia, without obstructions or shade, and approximately two kilometres from the university. The International Radiation Protection Association established exposure limits (EL) in its recreational/occupational UV exposure standard in 1985. These were later adopted by the International Commission on Non-Ionizing Radiation Protection (ICNIRP) and updated in 2004. The ICNIRP recommends a maximum personal daily exposure of $30 \mathrm{~J} / \mathrm{m}^{2}$ effective UV dose within an 8-hour period for a sensitive unprotected skin using the American Conference of Governmental Industrial Hygienists (ACGIH) action spectrum. This American scale differs 
from the International Commission on Illumination (CIE) action spectrum (McKinlay and Diffey 1987) to which the spectral sensitivity of the spore film dosimeter used in our study corresponds. The relationship between CIE and ACGIH applied here, as can be found in Serrano et al. (2009), is that the effective ACGIH exposure $\left(30 \mathrm{~J} / \mathrm{m}^{2}\right)$ is equal to an effective CIE exposure of $109 \mathrm{~J} / \mathrm{m}^{2}$ per 8-hour period.

\section{Statistical analysis}

Data was analyzed using the Statgraphics Plus software v5.1 statistical package and is expressed as a median $(25,75$ percentile). The Wilcoxon-Mann-Whitney contrast test was used to compare medians and compare differences between two samples in terms of UVER doses, ER, or SED per hour outdoors. The Kruskall-Wallis test was used to compare differences between more than two groups in the same terms. Statistical significance was set at $\mathrm{p} \leq 0.05$ for all analyses.

\section{Results}

\section{Ambient solar UVER}

Temperature data provided by the state weather agency (Agencia Estatal de Meteorología 2010) for each day of the study is shown in Table 2, as well as ozone data obtained from the Ozone Monitoring Instrument (OMI, NASA) and the UV index (UVI) (ICNIRP 1995; WHO 2002) from the GV UVER $\left(\mathrm{W} / \mathrm{m}^{2}\right)$ station. As can be seen from the table, solar UVI is quite 
high (between 8 and 9), which is normal for the time of year in Valencia. The total column ozone from the OMI measurements for Valencia varies from 295 D.U. on 23 July, 2008, to 322 D.U. on 15 July, 2008. Mean solar height at noon during July is 71.7 degrees in the city of Valencia.

$<$ Table 2>

Measurements of daily ambient solar UVER were recorded by a radiometer belonging to the GV regional government weather station.

\section{Measured UVER exposures}

Table 3 shows that the median $(25,75$ percentile) two-day measured dosimeter exposures in SEDs for all groups was $5.49(3.59,8.00)$. Also given is a summary of the ambient UVER as measured by the dosimeters in SEDs. The children's median outdoor UV exposure per hour was $1.13(0.81,1.84)$ SEDs. Also interesting is the fraction of the ambient radiation (ER) that the subjects were exposed to: $5.9(4.1,8.7) \%$ for the entire period. The results discussed above were classified by age. No statistical difference with regard to UVER exposure (studied as outdoor UV exposure per hour) was found between the children of each group ( $\mathrm{p}=0.99$ Kruskall-Wallis test).

\section{$<$ Table 3>}

The interquartile range shown in Table 3 is a measure of statistical dispersion and indicates a strip that includes $50 \%$ of the population. Children in group 2 had the highest value for the 
interquartile range corresponding to UVER exposure measurements, indicating that children in group 2 behaved less consistently than the other groups.

$<$ Table 4>

Table 4 summarizes the same type of results for the monitors: namely, UVER exposure given in SEDs and the ER of the wrist dosimeters. The UVER exposure, as outdoor UV exposure per hour, received by all the monitors was similar statistically $(\mathrm{p}=0.56)$ to that received by all the children of the other groups: namely, 1.24 compared to 1.06 SEDs. In addition, no statistical difference $(\mathrm{p}=0.77)$ was found regarding the dosimeter position when calculated as ER $(5.7 \%$ compared to $6.3 \%)$.

Interquartile range of the median UVER exposure is higher for children than for monitors as is shown in Tables 3 and 4. This information gives a measure of the variability from day to day, and shows that children are less consistent in their activities than the monitors.

\section{Discussion}

It is difficult to compare results of studies on UV exposure in children due to differences such as the position and type of the anatomical dosimeters, latitude, season, and age group. For this reason, ER was chosen to minimize the effects on the analysis of season, latitude, and time of day. We compared our results with other studies made in the summer - although not at summer schools. The results of this study are somewhat different from those of Guy et al. (2003), who found $2.8 \%$ ambient UVER exposure on the collarbone for 7 to 9 year-olds, during a summer in South Africa. In our study, using children with dosimeters on the shoulder, we obtained $6.7 \%$ 
for 7 to 8 year-olds. In Australia, Kimlin et al. (2001) recorded approximately 4.6\% ambient UVER exposure for 8 year-old schoolchildren on the shoulder during late summer. In Japan (Ono et al. 2005), the weekly mean of daily UV exposure in summer (July) is in a range 91$170 \mathrm{~J} / \mathrm{m}^{2}$ for 8 to 9 year-old schoolchildren, approximately one-third of our measurements (266-324 J/m²). In Denmark (Thieden et al. 2004), the ER in July was $6.4 \%$ for all study subjects, and for children from 4-15 years old the percentage was similar to ours (5.9\%). In the same location of this paper (Serrano et al. 2011), the ER in late spring was 4.5-6.1\% for children from 6 to 11 years old, and it is similar to this study with an ER of 5.9\% for all children.

From the comparison we have made with other works in the summer and although there are differences in the position of the dosimeter, we can conclude that schoolchildren receive from 3 to $6 \%$ of the ambient UVER in the summer period.

Children in the summer school are divided into groups according to their age. Each age group is assigned a minimum of two people (monitors) for the control of children and consisted of 20 students per group. We have used a sample of 5 students per group, i.e. $25 \%$, which we consider suitable for this type of analysis because all members of the group performed the same activities, at the same time and in the same place. Therefore, we believe that a sample of $25 \%$ of the students is appropriate for analyzing the behaviour of children in the summer school.

The three age groups were compared for UVER exposure (studied as outdoor UV exposure per hour) and we did not found statistical differences between them.

No significant differences were found between the monitors and the children with regard to UVER exposure. For this reason, if we consider the differing dosimeter positions of the 
monitors and children, and given that the time both groups were outside was the same, we conclude that there were no significant differences for UVER exposure between wrist dosimeters (monitors) and shoulder dosimeters (children).

Median daily UV exposure for all groups was 2.74 SEDs. Therefore, exposure exceeded 1 SED by a factor of 2.7, so that children received approximately three times the expected UVER load for unprotected skin and eyes in their daily outdoor activities in the summer school. This confirms that protective measures are very necessary.

Median daily UV exposure for all the monitors was 2.52 SEDs. Therefore, this exposure exceeded exposure limits for outdoor workers by a factor of about 2.5 , so that the summer school monitors received approximately twice the expected UVER load for unprotected skin and eyes. This indicates that protective measures are also necessary for the monitors. Although children spend up to 2-3 hours per day exposed to UV radiation in the summer school, it is possible for the monitors to help the children partially avoid UV exposure by looking for shade near trees and buildings. The use of sunscreens and protective clothing are also advisable protective strategies.

The recommendations for UV minimisation based on this research would be targeted at those responsible for the organization and development of leisure activities and free time of the UPV summer school, to take into consideration to increase the number of indoor activities and that outdoor activities take place near trees and shade structures, and so to increase the amount of shade. Thus, students could enjoy recreational spaces without receiving much solar radiation. This information has been sent to the heads of the UPV summer school so that, within its capabilities, take action to reduce the level of radiation received by the children and provide adequate information to the monitors to take protective measures. 
In conclusion, a personal VioSpor film dosimeter was used to measure the recreational UV exposure of children in a summer school, and the children were found to far exceed international UV exposure limits. These high exposure values suggest an increased risk of skin cancer, as sunlight exposure is believed to be more crucial during youth for the development of cutaneous melanoma than later in life.

\section{Acknowledgments}

The authors wish to thank the monitors and children of the summer school for their cooperation in this study. We are also grateful to the national weather agency and the Generalitat Valenciana for providing us with access to weather data.

We would like to thank the Linguistic Assistance Office, Universidad Politécnica de Valencia (Spain) for granting financial support for the proof-reading of this paper.

The research reported here was supported by the Spanish Ministry of Education and Science within the research project CGL2007-61813 and the Generalitat Valenciana within the project PROMETEO/2010/064 


\section{References}

Agencia Estatal de Meteorología. http://www.aemet.es/. Accessed 5 March 2010

Armstrong BK (2005) How sun exposure causes skin cancer: an epidemiological perspective, In Prevention of Skin Cancer (Edited by D. Hill, J. M. Elwood and D. R. English). Kluwer Academic pp. 89-116

Armstrong BK, Kricker A (2001) The epidemiology of UV induced skin cancer. J Photochem Photobiol B 63: $8-18$

Biosense Laboratories. http://www.biosense.de/viosp-e.htm. Accessed 5 March 2010

Boldeman C, Dal H, Wester U. (2004) Swedish pre-school children's UVR exposure - a comparison between two outdoor environments. Photodermatol. Photoimmunol. Photomed., 20: $2-8$.

Fitzpatrick TB, Pathak M, Parrish JA (1974) Protection of human skin against the effects of the sunburn ultraviolet (290- $320 \mathrm{~nm})$. In Sunlight and Man: Normal and Abnormal Photobiologic Responses (Edited by M. A. Pathak, L. C. Harber, M. Seiji and A. Kukita) University of Tokyo Press, Tokyo, pp. 751

Furusawa Y, Quintern LE, Holtschmidt H, Koepke P, Saito M (1998) Determination of erythemaeffective solar radiation in Japan and Germany with a spore monolayer film optimized for the 
detection of UVA and UVA - results of a field campaign. Appl Microbiol Biotechnol 50: 597603

Gies P, Roy C, Toomey S, MacLennan R, Watson M (1998) Solar UVR exposures of primary schoolchildren at three locations in Queensland. Photochem Photobiol 68: 78-83

Grant WB, Holick MF (2005) Benefits and requirements of vitamin D for optimal health: a review. Alternative Medicine Review 10(2): 94-104

Guy CY, Diab RD, Martincigh BM (2003) Ultraviolet radiation exposure of children and adolescents in Durban, South Africa. Photochem Photobiol 77: 265-270

IARC, IARC monographs on the evaluation of carcinogenic risks to humans: solar and ultraviolet radiation 55, Lyon, 2000

International Commission on Non-Ionizing Radiation Protection (1995) Global Solar UV Index. ICNIRP-1/95

International Commission on Non-Ionizing Radiation Protection (ICNIRP) (2004) Guidelines on Limits of Exposure to Ultraviolet Radiation of Wavelengths between $180 \mathrm{~nm}$ and $400 \mathrm{~nm}$ (Incoherent Optical Radiation). Health Physics 87 (2): 171-186 
Kimlin M, Parisi A (2001)Usage of real-time ultraviolet radiation data to modify the daily erythemal exposure of primary schoolchildren. Photodermatol Photoimmunol Photomed 17: $130-135$

McKinlay AF, Diffey BL (1987) A reference action spectrum for ultraviolet induced erythema in human skin. CIE Journal 6: 17-22

Moehrle M, Dennenmoser B, Garbe C (2003) Continuous long-term monitoring of UV radiation in Professional mountain guides reveals extremely high exposure. Int J Cancer 103: 775-778

Moehrle M, Garbe C (2000) Personal UV dosymetry by Bacillus subtilis Spore Films. Dermatology 200: 1-5

Moehrle M, Korn M, Garbe C (2003) Bacillus subtilis spore film dosimeters in personal dosimetry for occupational solar ultraviolet exposure. Int Arch Occup Environ Health 173: 575-580

Munakata N, Ono M, Watanabe S (1998) Monitoring of Solar-UV Exposure among Schoolchildren in Five Japanese Cities using Spore Dosimeter and UV-coloring Labels. Jpn J Cancer Res 89: 235-245

NASA, Total Ozone Mapping Spectrometer. http://jwocky.gsfc.nasa.gov/.Accessed 1 April 2010 
Norval M, CullenAP, de Gruijl FR, Longstreth J, Takizawa Y, Lucas RM, Noonan FP, van der Leun (2007) The effects on human health from stratospheric ozone depletion and its interactions with climate change. Photochem Photobiol Sci 6: 232-251

Oliveria SA, Saraiya M, Geller AC, Heneghan MK, Jorgensen C (2006) Sun exposure and risk of melanoma. Arch Dis Child 91:131-138

Ono M, Munakata N, Watanabe S (2005) UV exposure of elementary school children in five Japanese cities. Photochem Photobiol 81: 437-445

Programa meteorología de la Fundación Centro de Estudios Ambientales del Mediterráneo (Generalitat Valenciana). http://www.gva.es/ceamet/vigilancia/radUV/radUV.html. Accessed 15 March 2010

Saraiya M, Glanz K, Briss PA, Nichols P, White C, Das D, Smith SJ, Tannor B, Hutchinson AB, Wilson KM, Ghandi N, Lee NC, Rimer B, Coates RC, Kerner JF, Hiatt RA, Buffler P, Rochester P (2004) Interventions to prevent skin cancer by reducing exposure to ultraviolet radiation: a systematic review. Am J Prev Med 27: 422-466

Serrano MA, Cañada J, Moreno JC (2009) Erythemal Ultraviolet exposure in two groups of outdoor workers in Valencia, Spain. Photochemistry and Photobiology 85: 1468-1473 
Serrano MA, Cañada J, Moreno JC (2010) Erythemal Ultraviolet exposure of cyclists in Valencia, Spain. Photochemistry and Photobiology 86: 716-721.

Serrano MA, Cañada J, Moreno JC (2011) Solar UV exposure of Primary Schoolchildren in Valencia, Spain. Photochem. Photobiol. Sci., 2011, DOI: 10.1039/C0PP00153H

The International Commission on Illumination, Standard Erythema Dose, a Review (1997). CIE Journal 125, Viena

The International Non-Ionizing Radiation Committee of the International Radiation Protection Association (1985) Guidelines on Limits of Exposure to Ultraviolet Radiation of Wavelengths between $180 \mathrm{~nm}$ and 400nm (Incoherent Optical Radiation). Health Physics 49 (2): 331-340

Thieden E, Ågren MS, Wulf HC (2000) The wrist is a reliable body site for personal dosimetry of ultraviolet radiation. Photodermatol Photoimmunol Photomed 16: 57-61

Thieden E, Philipsen PA, Heydenreich J, Wulf HC (2004) UV radiation exposure related to age, sex, occupation, and sun behaviour based on time-stamped personal dosimeter readings. Arch Dermatol 140: 197-203.

World Health Organization (2002) Global Solar UV Index: A Practical guide. WHO, Geneva, Switzerland. 
Wright C, Reeder A (2005) Youth solar ultraviolet radiation exposure, concurrent activities and sun-protective practices: A review. Photochem Photobiol 81: 1331-1342.

Wright CY, Reeder AI, Bodeker GE, Gray A, Cox B. (2007) Solar UVR exposure, concurrent activities and sun-protective practices among primary schoolchildren. Photochem. Photobiol. 83: 749-758. 
Table 1 Measurement dates for each group and number of children who participated in the study from each age group

\begin{tabular}{ccc}
\hline $\begin{array}{c}\text { Group (number } \\
\text { children ) }\end{array}$ & Aeasurement dates \\
\hline G1 (5) & $10,18,22,23,29,30$ July 2008 & $7-8$ years \\
G2 (5) & $8,10,15,30$ July 2008 & $9-10$ years \\
G3 (5) & $8,11,23,30$ July 2008 & $11-12$ years \\
\hline
\end{tabular}


Table 2 Mean temperature (with maximum and minimum quoted in parenthesis), ozone concentration data from Ozone Monitoring Instrument (NASA), ambient UVER and UV index from the UVER (SEDs) YES UVB-1 radiometer located at the Generalitat de Valencia weather station

\begin{tabular}{ccccc}
\hline Date & Air temperature & Ozone & Ambient UVER & UVI \\
& $\left({ }^{\circ} \mathrm{C}\right)$ & (Dobson units) & (SEDs) & \\
\hline $08 / 07 / 2008$ & $24.9(27-23.4)$ & 296 & 45.10 & 9 \\
$10 / 07 / 2008$ & $24.9(27.7-21.4)$ & 298 & 43.44 & 8 \\
$11 / 07 / 2008$ & $25.7(29.7-22.8)$ & 300 & 47.21 & 8 \\
$15 / 07 / 2008$ & $23.2(26.6-19.1)$ & 322 & 43.13 & 8 \\
$18 / 07 / 2008$ & $23.6(26.7-18.9)$ & 308 & 32.61 & 9 \\
$22 / 07 / 2008$ & $25.1(27.1-23.4)$ & 299 & 44.86 & 8 \\
$23 / 07 / 2008$ & $25.0(28.1-21.7)$ & 295 & 43.13 & 8 \\
$29 / 07 / 2008$ & $27.2(28.6-24.8)$ & 317 & 41.54 & 8 \\
$30 / 07 / 2008$ & $26.9(28.3-26.1)$ & 316 & 42.27 & \\
\hline
\end{tabular}


Table 3 UVER exposures and ambient UVER (both given in SEDs) for two days, measured using Viospor dosimeters, and Exposure ratio for all groups

\begin{tabular}{|c|c|c|c|c|}
\hline & UVER exposure & SED/Hour outdoor & Median & Exposure ratio \\
\hline & Median $(25,75$ percentile $)$ & Median $(25,75$ & Ambient UVER & Median $(25,75$ \\
\hline & (SEDs) & percentile) & (SEDs) & percentile) $(\%)$ \\
\hline \multicolumn{5}{|l|}{ Group 1} \\
\hline $10,18 / 07 / 2008$ & 4.54 & 1.14 & 79.15 & 5.7 \\
\hline $22,23 / 07 / 2008$ & 7.54 & 1.89 & 112.15 & 6.7 \\
\hline $22,23 / 07 / 2008$ & 6.54 & 1.01 & 82.32 & 7.9 \\
\hline Total for group 1 & $6.49(3.95,8.42)$ & $1.14(0.82,1.75)$ & 82.32 & $6.7(4.9,8.9)$ \\
\hline \multicolumn{5}{|l|}{ Group 2} \\
\hline $8,10 / 07 / 2008$ & 5.37 & 1.34 & 93.80 & 5.7 \\
\hline $15,30 / 07 / 2008$ & 4.87 & 0.97 & 92.96 & 5.2 \\
\hline Total for group 2 & $5.31(4.26,8.04)$ & $1.33(0.85,1.90)$ & 92.96 & $5.7(4.6,8.6)$ \\
\hline \multicolumn{5}{|l|}{ Group 3} \\
\hline $8,10 / 07 / 2008$ & 5.70 & 1.27 & 94.46 & 6.0 \\
\hline $15,30 / 07 / 2008$ & 5.03 & 1.12 & 90.03 & 5.6 \\
\hline Total for group 3 & $5.37(3.77,7.8)$ & $1.19(0.84,1.73)$ & 92.95 & $5.8(4.2,8.6)$ \\
\hline All groups & $5.49(3.59,8.00)$ & $1.13(0.81,1.84)$ & 92.96 & $5.9(4.1,8.7)$ \\
\hline
\end{tabular}


Table 4 Monitors UVER exposure given in SEDs measured using Viospor dosimeters for each subject for two days for the summer school period

\begin{tabular}{ccccc}
\hline Monitor & Median time spent & UVER exposure & SED/Hour Outdoor & Exposure ratio \\
& Outdoor 2 days & Median (25,75 percentile) & Median $(25,75$ & Median (25,75 \\
& (h) & (SEDs) & percentile) & percentile) $(\%)$ \\
\hline G1 & 4.00 & 5.03 & 1.24 & 6.3 \\
G2 & 4.50 & 7.00 & 1.67 & 7.5 \\
G3 & 4.50 & 5.00 & 1.11 & 5.4 \\
\hline All monitors & 4.50 & $5.03(4.49,6.94)$ & $1.24(0.87,1.65)$ & $6.3(5.2,6.8)$ \\
\hline
\end{tabular}

